\title{
Development of Control Structure for Hybrid Wind Generators with Active Power Capability
}

\author{
Mehdi Niroomand ${ }^{1}$ and Dong-Jun Won ${ }^{2}$ \\ ${ }^{1}$ Department of Electrical Engineering, University of Isfahan (UI), Isfahan, Iran \\ ${ }^{2}$ Department of Electrical Engineering, INHA University, Incheon, Republic of Korea \\ Correspondence should be addressed to Dong-Jun Won; djwon@inha.ac.kr
}

Received 4 March 2014; Revised 20 July 2014; Accepted 20 July 2014; Published 2 September 2014

Academic Editor: Antonio J. Marques Cardoso

Copyright (c) 2014 M. Niroomand and D.-J. Won. This is an open access article distributed under the Creative Commons Attribution License, which permits unrestricted use, distribution, and reproduction in any medium, provided the original work is properly cited.

\begin{abstract}
A hierarchical control structure is proposed for hybrid energy systems (HES) which consist of wind energy system (WES) and energy storage system (ESS). The proposed multilevel control structure consists of four blocks: reference generation and mode select, power balancing, control algorithms, and switching control blocks. A high performance power management strategy is used for the system. Also, the proposed system is analyzed as an active power filter (APF) with ability to control the voltage, to compensate the harmonics, and to deliver active power. The HES is designed with parallel DC coupled structure. Simulation results are shown for verification of the theoretical analysis.
\end{abstract}

\section{Introduction}

To have sustainable growth and social progress, it is necessary to fulfil the energy need by utilizing the renewable energy resources like wind, photovoltaic, biomass, hydro, cogeneration, and so forth [1]. Wind energy is one of the most important renewable energy sources on earth. During the last decade, there has been heavy growth in both the size and the power of wind energy converters $[1,2]$.

In normal operation, wind turbine produces a continuous variable output power. These power variations are mainly caused by the effect of turbulence, wind gradient, and towershadow and control system in the power system. Thus, the network needs to manage for such fluctuations. In the event of increasing grid disturbance, an energy storage system (ESS) for wind energy generating system is generally required to compensate the fluctuation generated by wind turbine [3].

In addition, when an ESS is added to a wind energy system, the grid-tie inverter in this system can exchange both active and reactive power with distribution system by varying the amplitude and phase angle of the converter voltage with respect to the line terminal voltage. This hybrid system can improve power quality of distribution system like an active power filter (APF) [4-8].

To achieve good ability of power quality improvement, a high performance control system should be designed for hybrid energy systems [8, 9]. Also, for good interaction between different sources, good power balancing should be considered. There are some researches about power balancing strategy and control algorithm for hybrid energy systems [10-16] and active power filters [17-19] that present some techniques. In this paper, a hierarchical control structure was proposed for hybrid energy systems. It consists of reference generation and mode select, power balancing, control algorithms, and switching control blocks. Also, a high performance power management strategy is used for the system. With this power balancing strategy, the system could easily provide ancillary services to grid and acting as an APF [10].

This paper is organized as follows. In Section 2, firstly, circuit diagrams of HES are reviewed. Then the proposed structure for HES and the structure of ESS were presented. Section 3 describes hierarchical control structure and power management system was proposed for the system. Finally, 


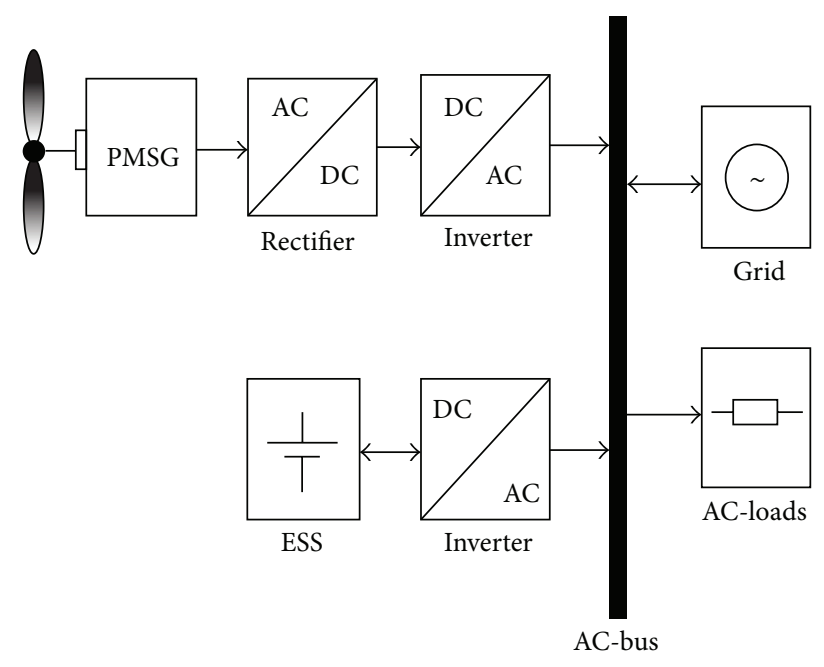

FIGURE 1: AC-coupled structure of HES.

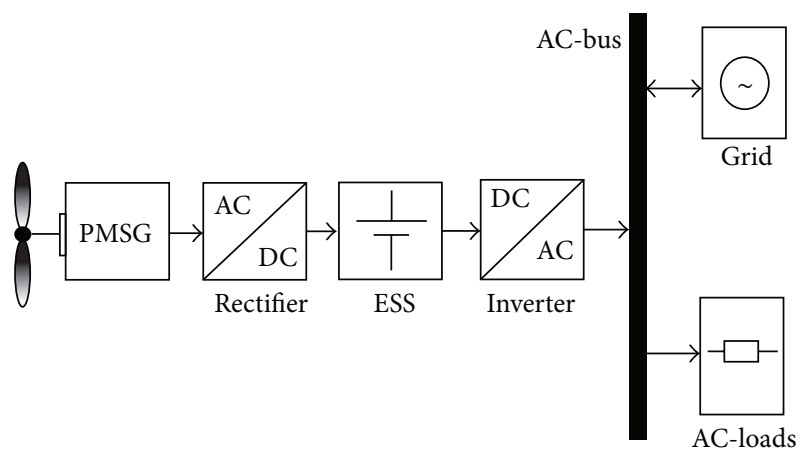

FIgUre 2: Cascade DC-coupled structure of HES.

simulation results and conclusion are presented in Sections 4 and 5 , respectively.

\section{Topology of HES}

2.1. Circuit Diagram. As mentioned in Introduction, HES can improve power quality of distribution system. There are some structures for HES. One structure that has been widely used is AC coupled structure [4]. Figure 1 shows circuit diagram of an AC coupled structure. This is a shunt-connected inverter and its DC link is supported using an ESS.

DC-coupled structure is another structure for HES. In DC-coupled structure the grid voltages and frequencies are decoupled from other sources. All sources are connected to a DC link before being connected to the grid through an inverter.

Cascade structure that has been widely used is based on the direct connection of a battery bank to the DC bus of the grid-connected inverter. Figure 2 shows cascade structure. In this structure, wind power is sent to the battery bank via a PWM rectifier. The stochastic nature of the wind power output and power demand leads to a fast charge/discharge action of batteries and fast battery aging [20].

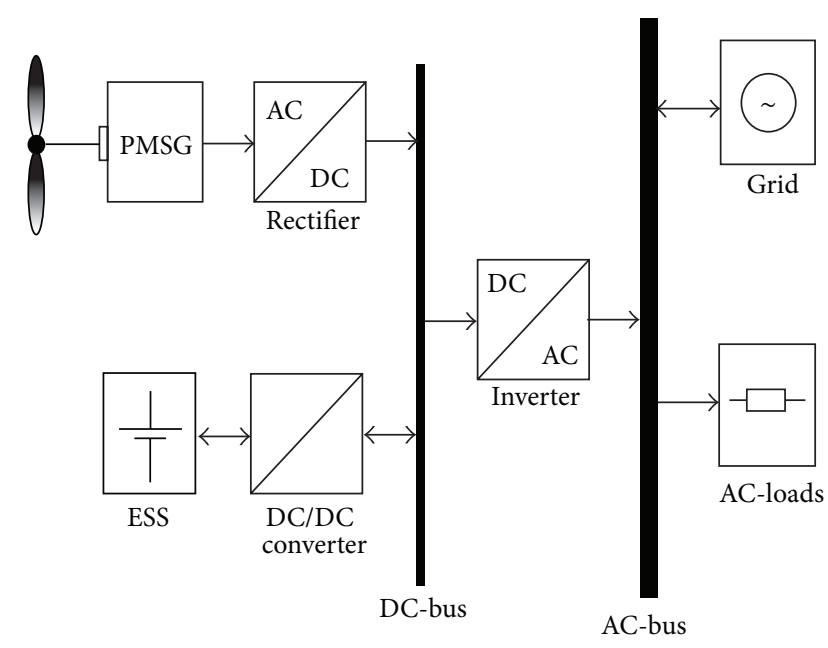

Figure 3: Parallel DC-coupled structure of HES.

To enable more efficient use of batteries, a parallel DCcoupled structure has been presented in researches [20, 21]. Figure 3 shows parallel DC-coupled structure. A first interest is that the battery bank is connected to the $\mathrm{DC}$ bus via a DC/DC converter, thus making it possible to obtain an optimized charge/discharge operation mode. A second advantage is that different energy storage can be added and is also connected to the DC bus via another DC/DC converter. In this paper, parallel DC-coupled structure is considered for proposed HES.

2.2. Energy Storage System Structure. In an HES, energy storage system plays an important role. It should supply needed power for fast fluctuation and long time instability. In this paper, in order to benefit from various technology advantages and its simplicity, a battery bank is considered [10, 22].

\section{Control System Structure}

As mentioned in Introduction, wind turbine produces a continuous variable output power and it causes some fluctuation in power system. An ESS can compensate some of this fluctuation. Also, when an ESS was added to a wind energy system, the grid-tie inverter in this system can exchange both active and reactive power with distribution system. This hybrid system can improve power quality of distribution system similar to an APF. Hence, the control system of an HES should have these capabilities.

3.1. Hierarchical Structure (Proposed Structure). The proposed control scheme for the HES has hierarchical structure. It consists of four blocks: reference generation and mode select, power balancing strategy, control algorithm, and switching control block. They are based on concepts of instantaneous power on the synchronous-rotating $d q$ reference frame as depicted in Figure 4. Rotating reference frame is used because it offers higher accuracy than stationary frame-based techniques [23]. All blocks make use of control 


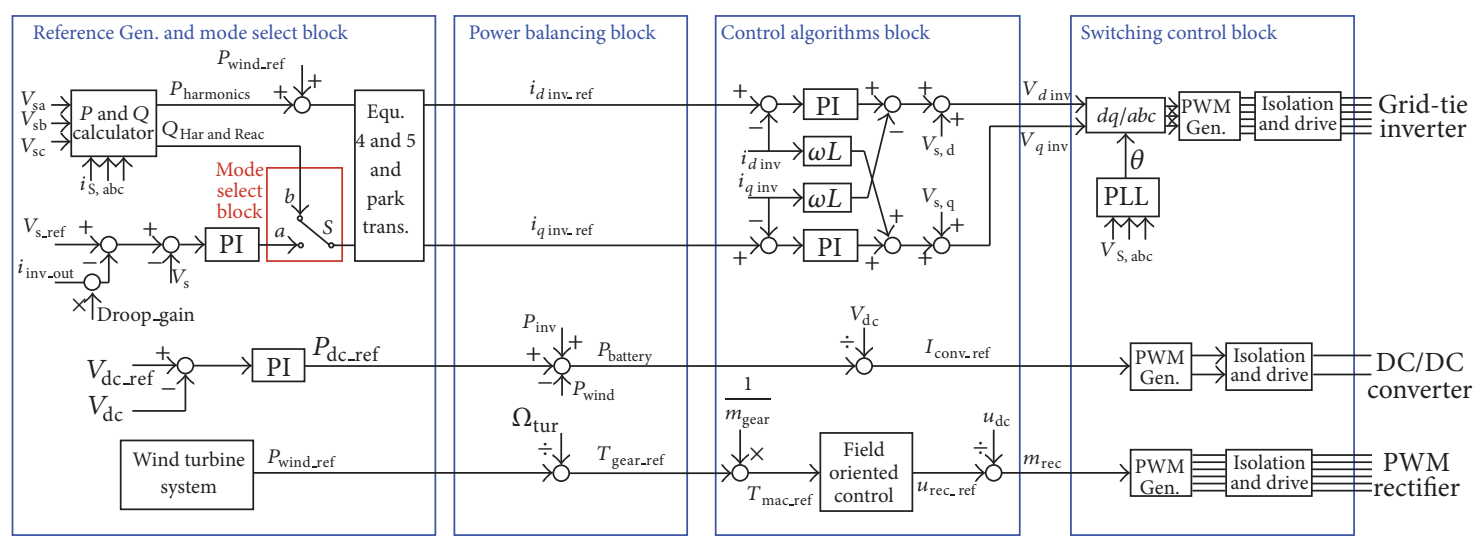

(a) (b) (c) (d)

FIGURE 4: The proposed hierarchical control structure for HES.

variables that are feasible to be locally measured. The following sections explains these blocks.

3.2. Reference Generation and Mode Select Block. The "reference generation and mode select" is responsible for determining the active and reactive power exchange between the HES and the utility system. Figure 4(a) shows the structure of this block. This block has two main modes: mode 1 and mode 2 . In mode 1 , HES can deliver active power to power system and also can enhance voltage profile by reactive power injection. In mode 2, HES can deliver active power to power system and also compensate harmonic parts of utility current to reach unity power factor.

In both modes, active reference is determined to control the active power exchanged with the electric system. In mode 1 , for generating active reference, the average power of wind system and stored energy was considered. But in mode 2, the active power required to compensate harmonic parts of nonlinear current was added.

Reactive reference in mode 1 is determined to control the voltage at the point of common coupling (PCC) of HES and power system. This control mode shows a very good performance in conventional static VAR compensators (with no energy storage). In this mode, a voltage regulation droop is used to allow the terminal voltage of the HES to vary in proportion with the compensating reactive current. The reference for terminal voltage including droop system is obtained as follows:

$$
v_{\text {sref_droop }}=v_{s_{\_} \text {ref }}-i_{\text {inv_out }} \times k_{\text {droop }} \text {, }
$$

where $i_{\text {inv_out }}$ is the output current of grid-tie inverter, $v_{s \_ \text {ref }}$ is the reference of line voltage, $k_{\text {droop }}$ is droop gain determined by user, and $v_{\text {sref_droop }}$ is the reference for terminal voltage.

Reactive reference in mode 2 was determined to compensate harmonic and reactive parts of load current. In this mode, the power factor of power system is equal to unity.
The active and reactive powers, which are exchanged with the grid, can be calculated through the "two-wattmeter" method [24]:

$$
\begin{gathered}
p_{g}=v_{13} i_{1}+v_{23} i_{2} \\
q_{g}=\sqrt{3}\left(v_{13} i_{1}-v_{23} i_{2}\right),
\end{gathered}
$$

where $v_{13}$ and $v_{23}$ are line to line voltages, $i_{1}$ and $i_{2}$ are line currents, and $p_{g}$ and $q_{g}$ are the active and reactive power exchanged between HES and grid. To generate current reference of inverter, currents should be extracted from (2) as follows:

$$
\begin{aligned}
& i_{1 \text { inv_ref }}=\frac{\left(2 v_{13}-v_{23}\right) p_{g_{\text {_ref }}}+\sqrt{3} v_{23} q_{g_{\text {_ref }}}}{2 v_{13}^{2}-2 v_{13} v_{23}+2 v_{23}^{2}} \\
& i_{2 \text { inv_ref }}=\frac{\left(2 v_{23}-v_{13}\right) p_{g_{\text {_ref }}}+\sqrt{3} v_{13} q_{g_{\text {_ref }}}}{2 v_{13}^{2}-2 v_{13} v_{23}+2 v_{23}^{2}} .
\end{aligned}
$$

Then, the $a b c$ currents should be transformed to synchronous reference frame with Park transform. With this block, proposed HES can improve power quality of distribution system, in addition to active power delivery.

3.3. Power Balancing Block. In this wind/ESS hybrid energy system, some power-electronic converters are used to regulate the power transfer with each source. According to a chosen power flow, the following two power balancing strategies were discussed in previous researches [10], "gridfollowing strategy" and "source-following strategy". In "gridfollowing strategy" the line-current loop is used to regulate the DC link voltage and in "source-following strategy" the line-current loop is used to control the grid active power, and also the DC bus voltage is regulated with the wind turbine system and ESS. Comparison of two control strategies shows the source following strategy has better performance on the grid power regulation than the grid-following strategy, and it can provide ancillary services according to the microgrid's requirements. In this paper, source following control strategy 


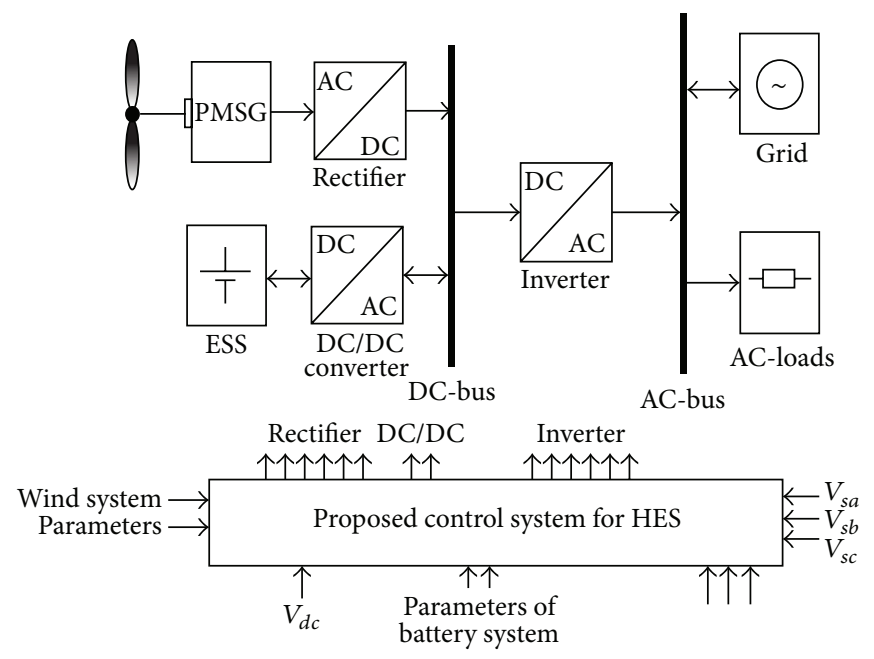

FIGURE 5: Block diagram of simulation setup.

is considered for the HES. Figure 4(b) shows the block diagram of this strategy.

In proposed HES, the reference of gear torque is determined by

$$
T_{\text {gear_ref }}=\frac{p_{\text {wind_ref }}}{\Omega_{\text {tur }}},
$$

where $T_{\text {gear_ref }}$ is the reference of gear torque of wind system, $\Omega_{\text {tur }}$ is rotational speed of gear, and $p_{\text {wind_ref }}$ is the reference of wind power. The main power balance equation is

$$
p_{\text {Battery }}=p_{\text {dc_ref }}+p_{\text {wind }}-p_{\text {inv }},
$$

where $p_{\text {Battery }}$ is power of battery, $p_{\text {wind }}$ is power of wind system, $p_{\text {inv }}$ is power of grid-tie inverter, and $p_{\mathrm{dc} \text { _ref }}$ is the required power for DC link voltage control.

As shown in Figure 4(b), in proposed power balance strategy, the references of currents of grid-tie inverter $\left(i_{d_{-} \text {inv_ref }}\right.$ and $\left.i_{q_{\text {_inv_ref }}}\right)$ are free for power quality improvement.

3.4. Control Algorithms Block. The control algorithms block makes the expected output to dynamically track the reference values set by the "reference generation and mode select block" and the "power balancing block." This block consists of current reference generation for ESS control, gear torque controller for wind power convection via PWM rectifier, and current control of grid-tie inverter.

The current control design is based on a linearization of the state-space averaged model of the grid-tie inverter. The basic equations governing the operation of this circuit in abcframe are

$$
\begin{aligned}
& v_{a}-v_{\mathrm{inv}_{a}}=L\left(\frac{d i_{L a}}{d t}\right), \\
& v_{b}-v_{\operatorname{inv}_{b}}=L\left(\frac{d i_{L b}}{d t}\right), \\
& v_{c}-v_{\text {inv } \_c}=L\left(\frac{d i_{L c}}{d t}\right),
\end{aligned}
$$

TABLE 1: System parameters.

\begin{tabular}{lc}
\hline Parameters & Ratings \\
\hline Grid voltage & 3-phase, $380 \mathrm{~V}, 50 \mathrm{~Hz}$ \\
Line series impedance & $L=.03 \mathrm{mH}, R=25 \mathrm{~m} \mathrm{ohm}$ \\
Load power & $150 \mathrm{kVA}$ \\
HES power & $100 \mathrm{kVA}$ \\
Wind system power & $30 \mathrm{~kW}$ \\
\hline
\end{tabular}

where $v_{a, b, c}$ are line voltages, $v_{\text {inv } a, b, c}$ are the output voltages of inverter, $L$ is the inductance of output filter of inverter, and $i_{L}$ is current of $L$. Rewriting (6) in synchronous rotating reference frame yields [23]

$$
\begin{aligned}
{\left[\begin{array}{l}
\frac{d i_{L d}}{d t} \\
\frac{d i_{L q}}{d t}
\end{array}\right]=\left[\begin{array}{cc}
0 & \omega \\
-\omega & 0
\end{array}\right] } \\
\\
\cdot\left[\begin{array}{l}
i_{L d} \\
i_{L q}
\end{array}\right]+\left[\begin{array}{ll}
\frac{1}{L} & 0 \\
0 & \frac{1}{L}
\end{array}\right]\left[\begin{array}{l}
v_{d}-v_{\text {inv_d }} \\
v_{q}-v_{\text {inv } q}
\end{array}\right],
\end{aligned}
$$

where $\omega=d \theta / d t$ is the synchronous angular velocity. Equation (7) shows a coupling term between $d$ and $q$ axes which influences the dynamic behaviour of the model. Therefore, in order to achieve a fully decoupled active and reactive power control, a feed-forward decoupled controller is used for inverter. Figure 4(c) shows this controller in detail.

Also, to extract the current reference for output current of $\mathrm{DC} / \mathrm{DC}$ converter, power of battery should be divided by DC link voltage as follows:

$$
i_{\text {conv_ref }}=\frac{p_{\text {Battery }}}{v_{\mathrm{dc}}},
$$




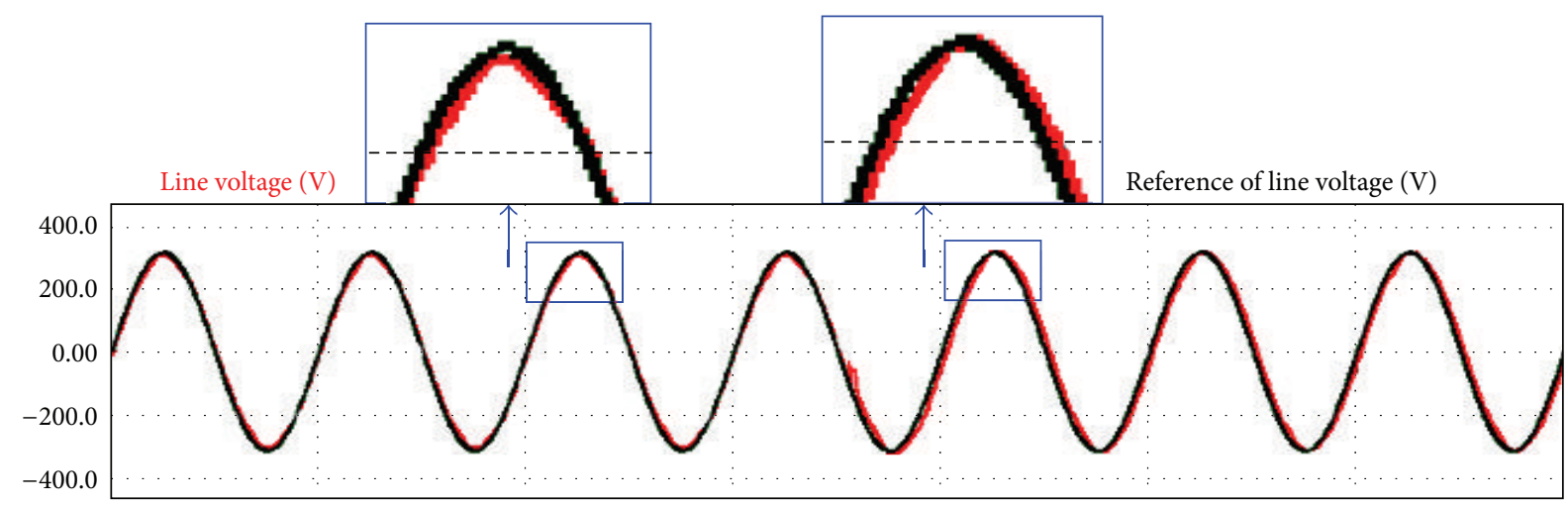

(a)

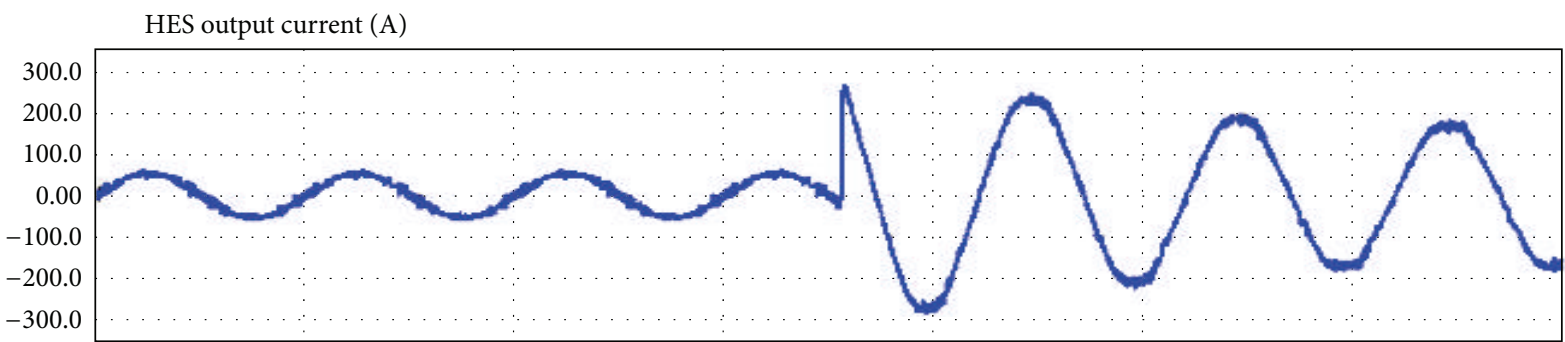

(b)

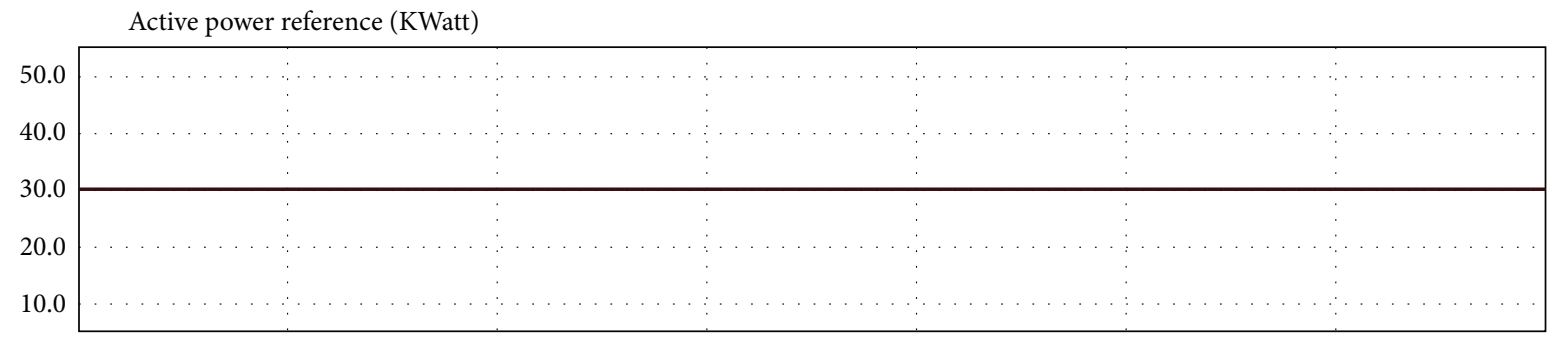

(c)

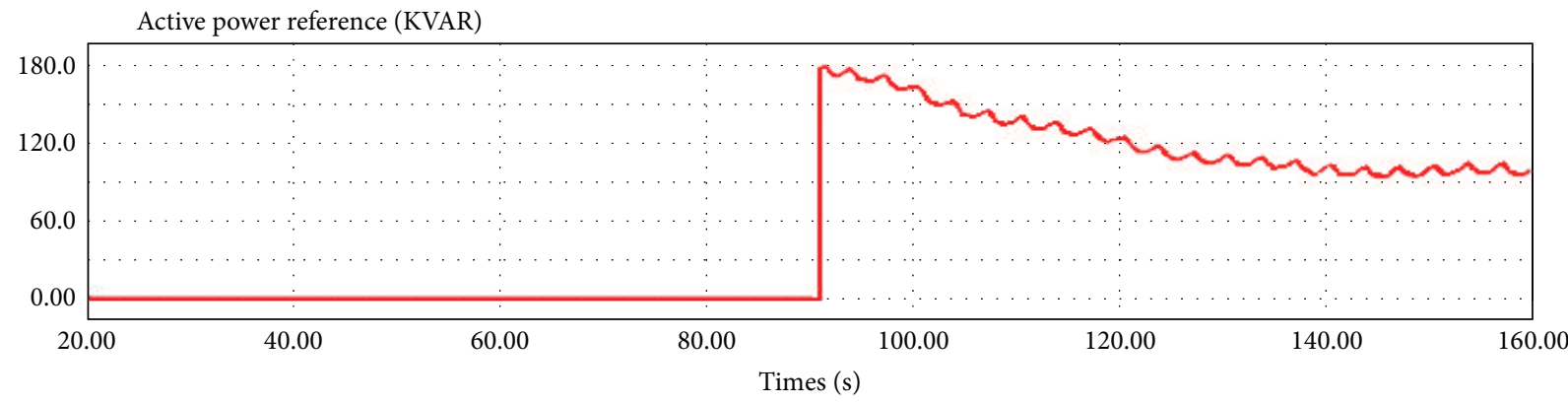

(d)

FIGURE 6: Simulation results, mode 1, voltage of PCC (before and after HES working).

where $i_{\text {conv_ref }}$ is reference of output current of $\mathrm{DC} / \mathrm{DC}$ converter and $v_{\mathrm{dc}}$ is DC link voltage.

3.5. Switching Control Block. Basic scheme of switching control block of proposed HES was shown in Figure 4(d). The switching control block provides dynamic control of input signals for inverter and DC/DC converter. This level is responsible for generating the triggering control signals for the switches of the inverter, according to the modulation techniques (SPWM) and types of semiconductors (IGBTs) and for the switches of DC/DC converter.

\section{Simulation Results}

Time-domain simulations are carried out to verify the theory described above and evaluate the performance of the proposed control structure. The simulations are performed using 


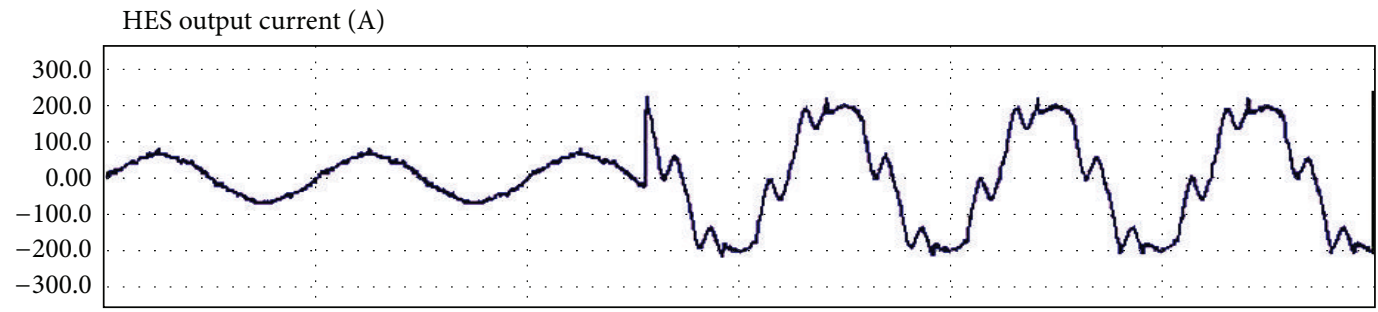

(a)

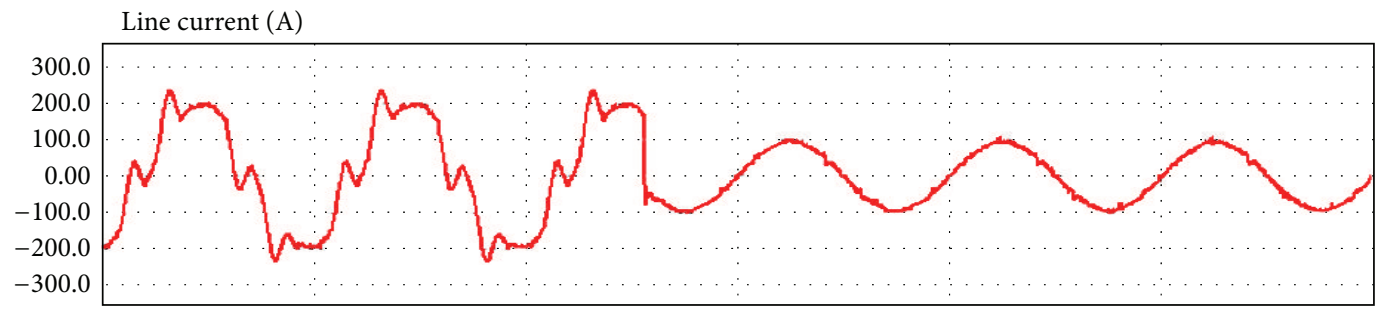

(b)

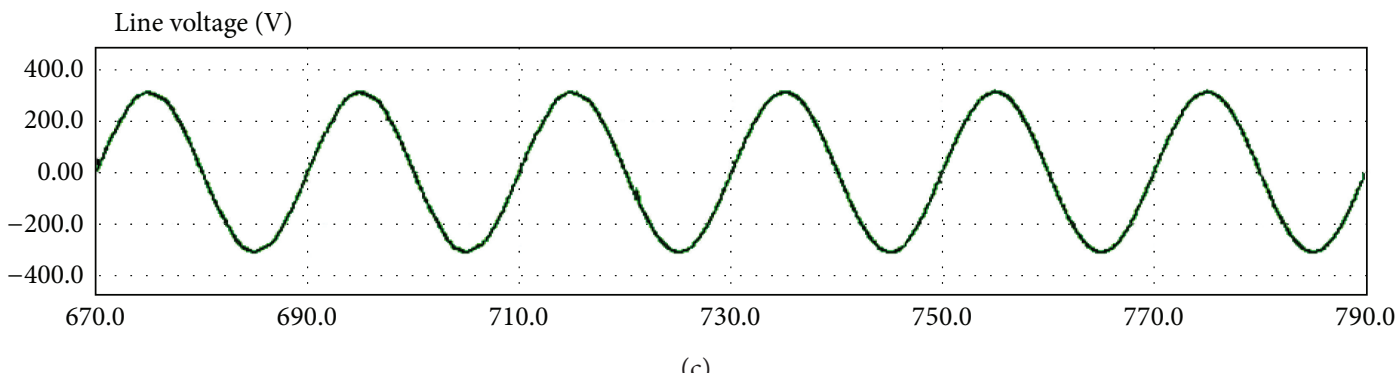

(c)

Figure 7: Simulation results, mode 2, (a) HES output current, (b) line current, and (c) line voltage.

PSIM software. Block diagram of simulation setup is shown in Figure 5 and parameters of the system are given in Table 1.

Figure 5 presents performance of system in mode 1. Before $t=90 \mathrm{~ms}$ HES works as a simple active generator. Before $t=90 \mathrm{~ms}$ line voltage is less than reference of line voltage (Figure 6(a)). After $t=90 \mathrm{~ms}$, HES works with proposed control system and profile of line voltage is enhanced (Figure 6(a)). A little difference between line voltage and reference of line voltage is caused by droop system. After $t=90 \mathrm{~ms}$, the active power reference is not changed, but reactive power reference is increased to compensate line voltage (Figures 6(b), 6(c), and 6(d)).

Figures 7 and 8 show the performance of system in mode 2. In Figure 7, before $t=720 \mathrm{~ms}$ HES works as a simple active generator. In this time, the current of HES is sinusoidal and line current is distorted by nonlinear loads. After $t=720 \mathrm{~ms}$ HES works with proposed control system. In this time HES compensates the reactive and harmonic parts of line current and line current is sinusoidal.

Figure 8 shows active and reactive power of HES and power system and its power factor. It can be obtained that, after HES was changed to mode 2, active power of HES was not changed significantly and only some variations were added to it (Figure 8(a)). Also, reactive power of HES was increased to compensate reactive and harmonic parts of loads (Figure 8(b)). Figure 8(e) shows power factor of power system. It can be found that HES could enhance power factor to unity.

The other set of simulations demonstrates the system performance in variable DC link voltage (Figure 9). This set simulates variation in DC link voltage caused by wind speed variation. Figure 9(a) shows good performance of HES, despite variation in DC link voltage (Figure 9(b)). This good performance is because of operation of controller. Figure 9(c) shows that when DC link voltage is low, output of controller is increased and when DC link voltage is high, output of controller is decreased.

\section{Conclusion}

In this paper, a parallel DC-coupled HES consists of WES and ESS has been studied. The multilevel control structure is divided into 4 blocks: (1) reference generation and mode select, (2) power balancing, (3) control algorithms, and (4) switching control. Source-following strategy was used for power management of this hybrid system. With this power balancing strategy, the system could easily provide ancillary services to grid and acts as an APF. Simulation results confirm the validity of analysis and design. 


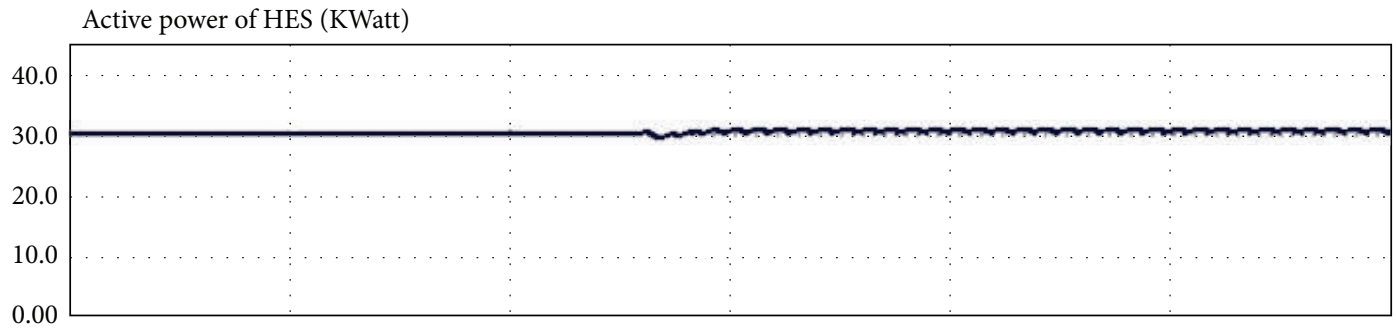

(a)

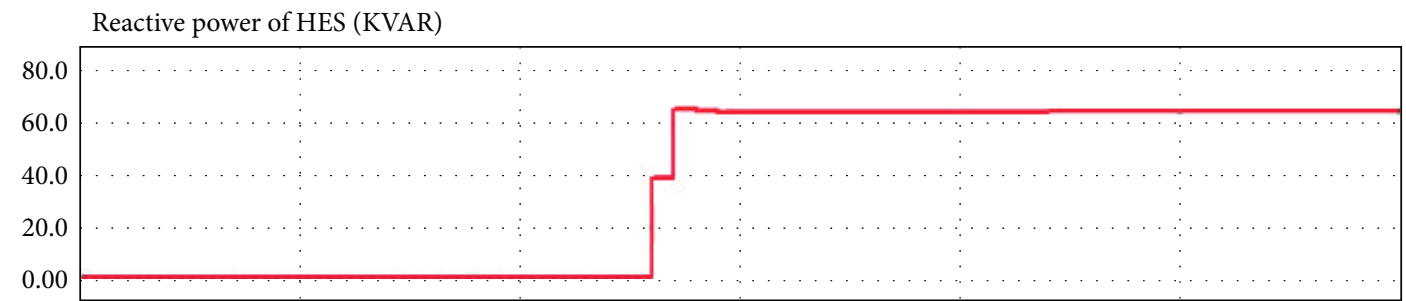

(b)

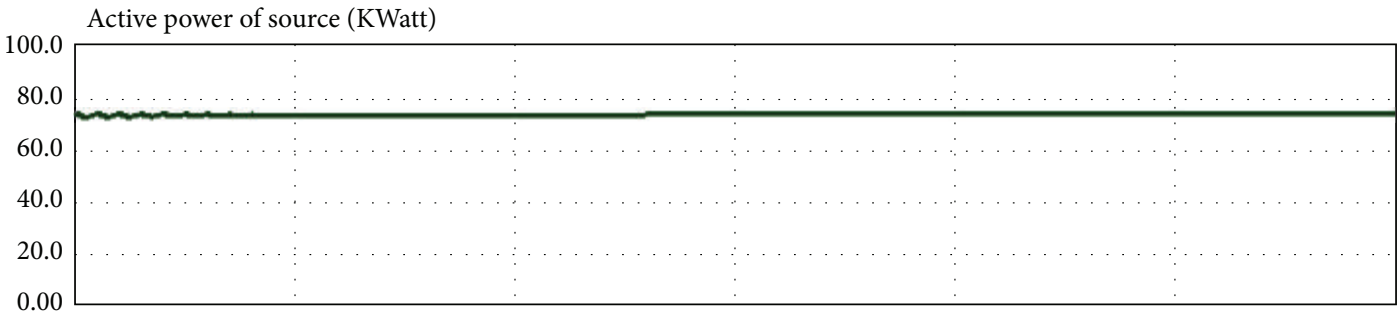

(c)

Reactive power of source (KVAR)

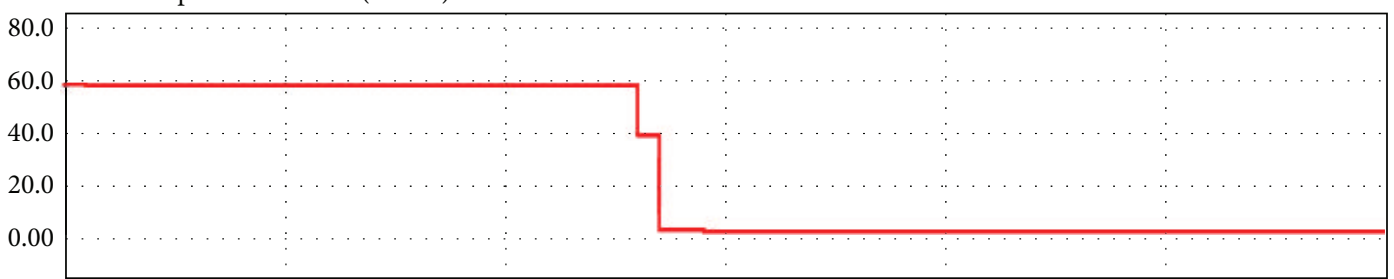

(d)

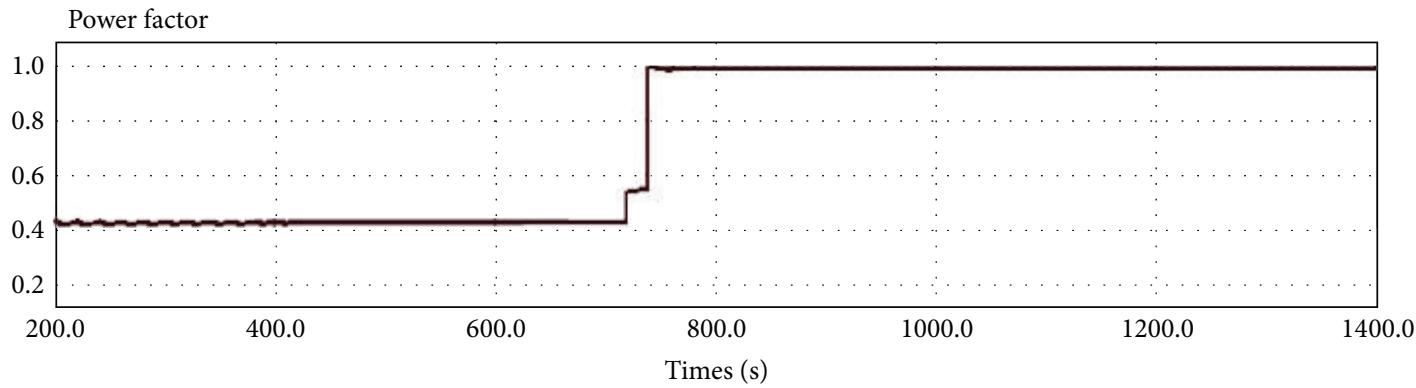

(e)

FIGURE 8: Simulation results, mode 2, (a) active power of HES, (b) reactive power of HES, (c) active power of source, (d) reactive power of source, and (e) power factor. 


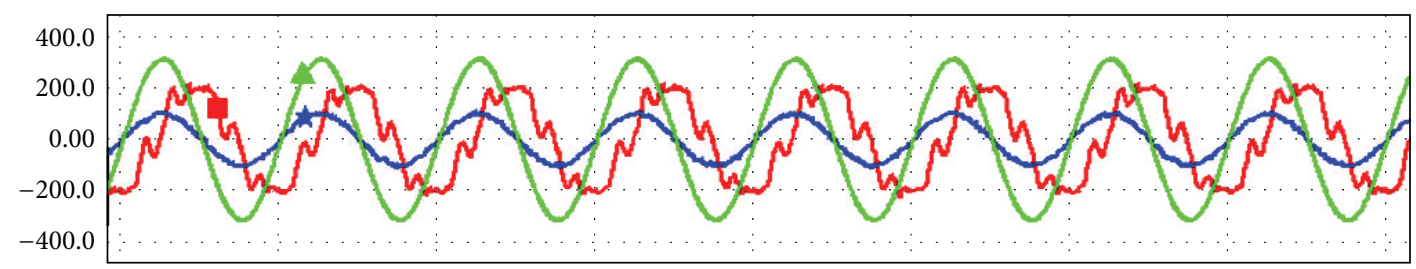

(a)

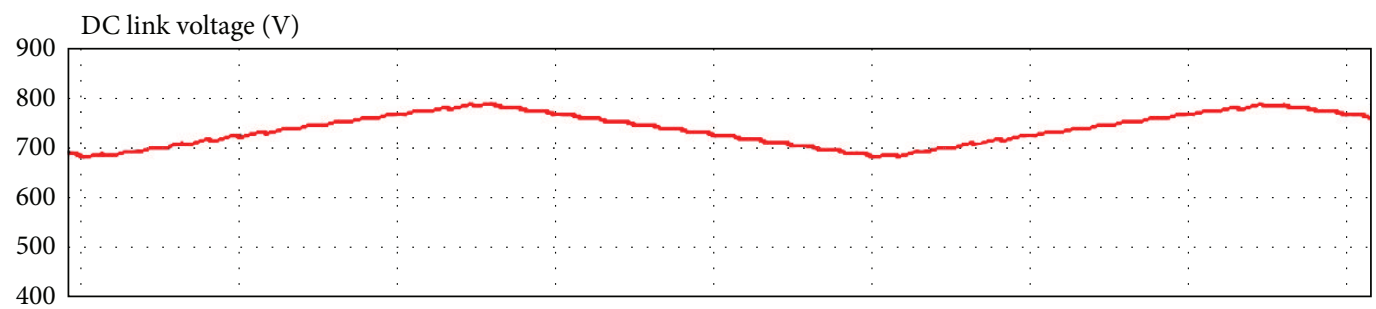

(b)

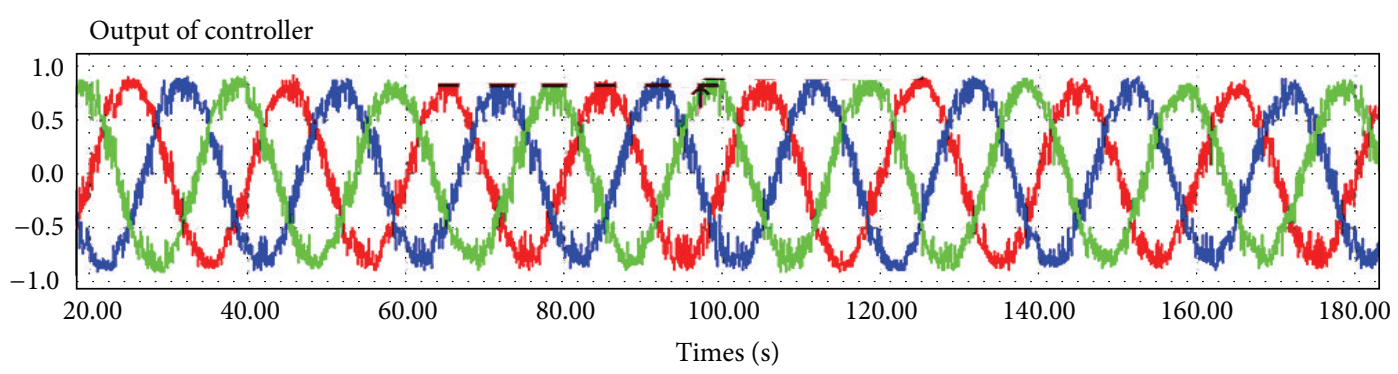

HES output current

Link voltage $(\mathrm{V})$

Link current (A)

(c)

FIGURE 9: Simulation results in variable wind speed (mode 2), (a) HES output current, line voltage, line current, (b) DC link voltage, and (c) outputs of controller.

\section{Conflict of Interests}

The authors declare that there is no conflict of interests regarding the publication of this paper.

\section{Acknowledgments}

This research was supported by Basic Science Research Program through the National Research Foundation of Korea (NRF) funded by the Ministry of Education, Science and Technology (Grant no. NRF-2013R1A1A1012667). This work was supported by the Human Resources Development program (no. 20111020400080) of the Korea Institute of Energy Technology Evaluation and Planning (KETEP) Grant funded by the Korea government Ministry of Trade, Industry and Energy.

\section{References}

[1] T. Ackermann, Wind Power in Power Systems, John Wiley \& Sons, London, UK, 2005.
[2] G. O. Suvire and P. E. Mercado, "Combined control of a distribution static synchronous compensator/flywheel energy storage system for wind energy applications," IET Generation, Transmission \& Distribution, vol. 6, no. 6, pp. 483-492, 2012.

[3] G. O. Suvire and P. E. Mercado, "Active power control of a flywheel energy storage system for wind energy applications," IET Renewable Power Generation, vol. 6, no. 1, pp. 9-16, 2012.

[4] P. Acuna, L. Moran, M. Rivera, J. Dixon, and J. Rodriguez, "Improved active power filter performance for renewable power generation systems," IEEE Transactions on Power Electronics, vol. 29, no. 2, pp. 687-694, 2014.

[5] H. Yi, F. Zhuo, Y. Zhang et al., "A source-current-detected shunt active power filter control scheme based on vector resonant controller," IEEE Transactions on Industry Applications, vol. 50, no. 3, pp. 1953-1965, 2014.

[6] M. Niroomand and H. R. Karshenas, "Performance specifications of series-parallel UPS's with different control strategies," International Review of Electrical Engineering, vol. 4, no. 1, pp. 14-21, 2009.

[7] A. F. Zobaa, "Optimal multiobjective design of hybrid active power filters considering a distorted environment," IEEE Transactions on Industrial Electronics, vol. 61, no. 1, pp. 107-114, 2014. 
[8] M. Niroomand and H. R. Karshenas, "Hybrid learning control strategy for three-phase uninterruptible power supply," IET Power Electronics, vol. 4, no. 7, pp. 799-807, 2011.

[9] F. Blaabjerg, R. Teodorescu, M. Liserre, and A. V. Timbus, "Overview of control and grid synchronization for distributed power generation systems," IEEE Transactions on Industrial Electronics, vol. 53, no. 5, pp. 1398-1409, 2006.

[10] T. Zhou and B. Francois, "Energy management and power control of a hybrid active wind generator for distributed power generation and grid integration," IEEE Transactions on Industrial Electronics, vol. 58, no. 1, pp. 95-104, 2011.

[11] B. Tudu, K. K. Mandal, and N. Chakraborty, "Optimal design and performance evaluation of a grid independent hybrid micro hydro-solar-wind-fuel cell energy system using meta-heuristic techniques," in Proceedings of the 1st International Conference on Non Conventional Energy (ICONCE '14), pp. 89-93, January 2014.

[12] T. Mhamdi and L. Sbita, "A power management strategy for hybrid photovoltaic diesel system with battery storage," in Proceedings of the 5th International Renewable Energy Congress (IREC '14), pp. 1-6, 2014.

[13] S. Sikkabut, N. H. Fuengwarodsakul, P. Sethakul et al., "Control strategy of solar/wind energy power plant with supercapacitor energy storage for smart DC microgrid," in Proceedings of the IEEE 10th International Conference on Power Electronics and Drive Systems (PEDS '13), pp. 1213-1218, April 2013.

[14] T. Mhamdi and L. Sbita, "A power management strategy for hybrid photovoltaic diesel system with battery storage," in Proceedings of the 5th International Renewable Energy Congress (IREC '14), pp. 1-6, Hammamet, Tunisia, March 2014.

[15] V. B. Virulkar and M. V. Aware, "Dstatcom with bess, an efficient means for flicker mitigation," in Proceedings of the IEEE Region 10 Conference (TENCON '08), pp. 1-6, November 2008.

[16] O. Ö. Mengi and I. H. Altaş, "Fuzzy logic control for a wind/ battery renewable energy production system," Turkish Journal of Electrical Engineering and Computer Sciences, vol. 20, no. 2, pp. 187-206, 2012.

[17] C. Schauder and H. Mehta, "Vector analysis and control of advanced static VAR compensators," IEE Proceedings C: Generation Transmission and Distribution, vol. 140, no. 4, pp. 299-306, 1993.

[18] B. Singh, K. Al-Haddad, and A. Chandra, "A review of active filters for power quality improvement," IEEE Transactions on Industrial Electronics, vol. 46, no. 5, pp. 960-971, 1999.

[19] H. Akagi, "New trends in active filters for power conditioning," IEEE Transactions on Industry Applications, vol. 32, no. 6, pp. 1312-1322, 1996.

[20] H. Fakham, D. Lu, and B. Francois, "Power control design of a battery charger in a hybrid active PV generator for load-following applications," IEEE Transactions on Industrial Electronics, vol. 58, no. 1, pp. 85-94, 2011.

[21] S. Younsi, M. Jraidi, N. Hamrouni, and A. Cherif, "Modelling and control of hybrid renewable energy system connected to AC grid," SOURCE International Journal on Computer Science \& Engineering (IJCSE), vol. 3, no. 12, p. 3854, 2011.

[22] M. G. Molina and P. E. Mercado, "Power flow stabilization and control of microgrid with wind generation by superconducting magnetic energy storage," IEEE Transactions on Power Electronics, vol. 26, no. 3, pp. 910-922, 2011.

[23] P. Vas, Vector Control of Ac Machines, Clarendon Press, New York, NY, USA, 1990.
[24] B. Walden, The Two Wattmeter Method for a Three-Wire Circuit, Ohio Semitronics, 2004. 

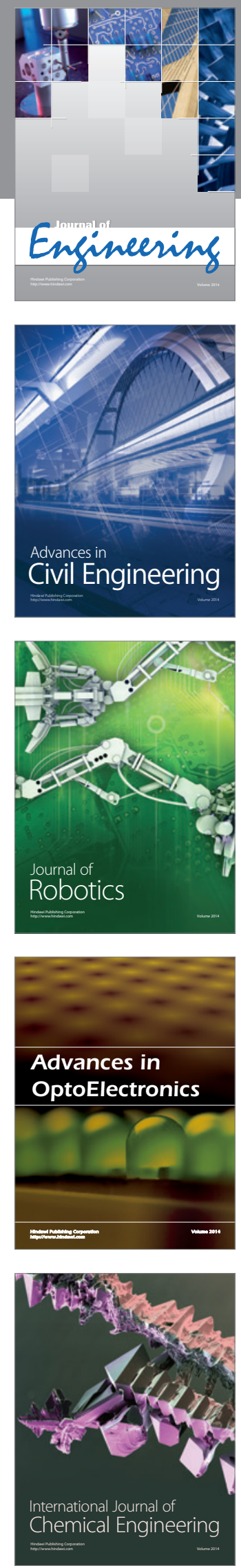

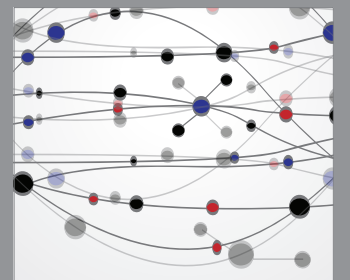

The Scientific World Journal
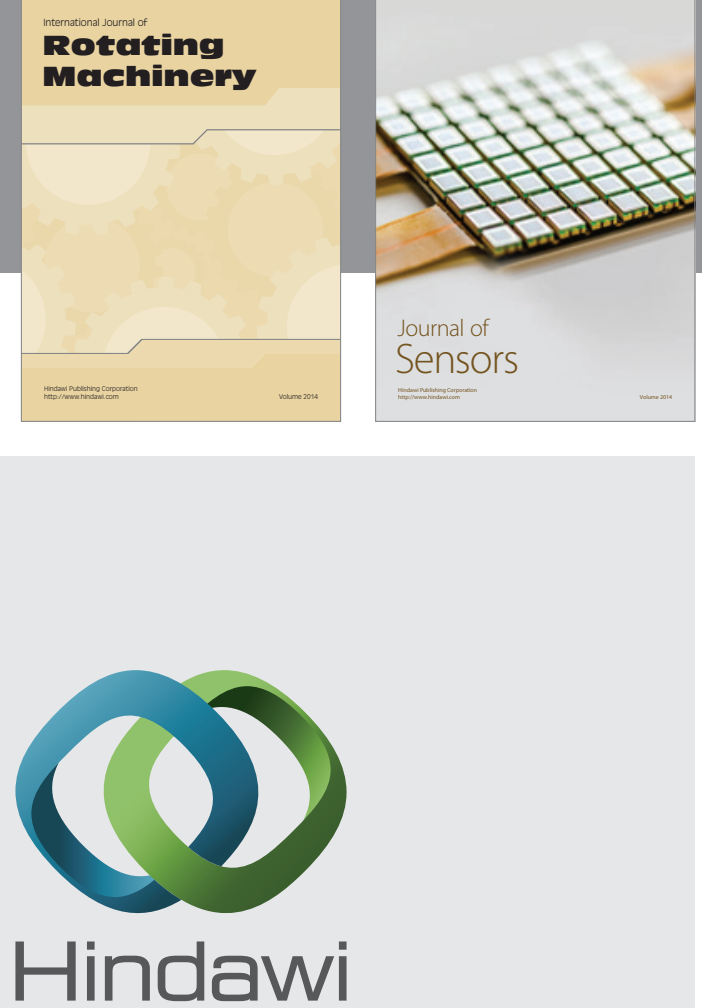

Submit your manuscripts at http://www.hindawi.com
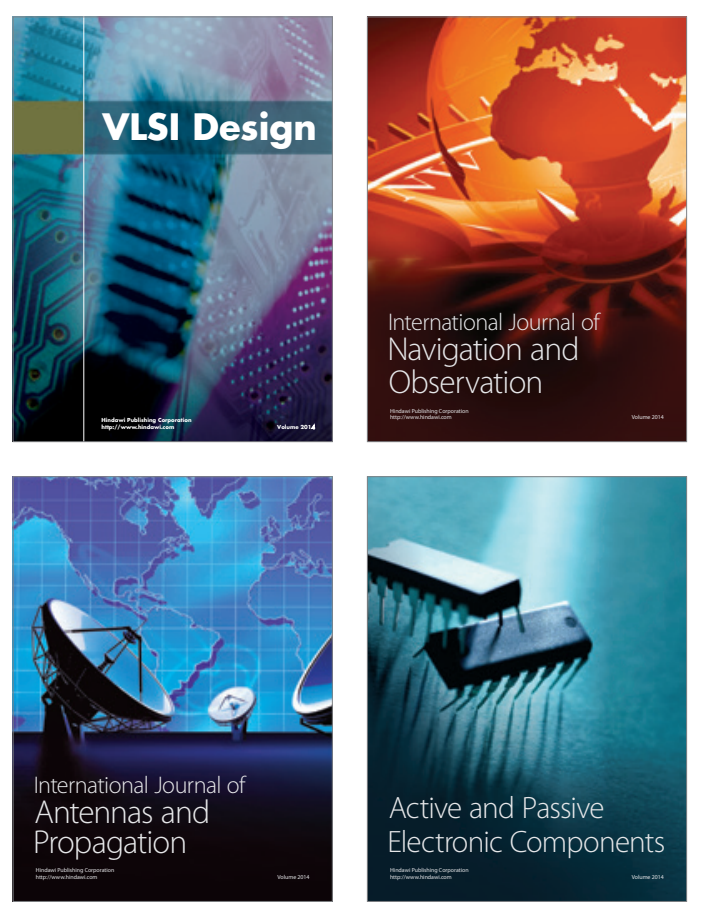
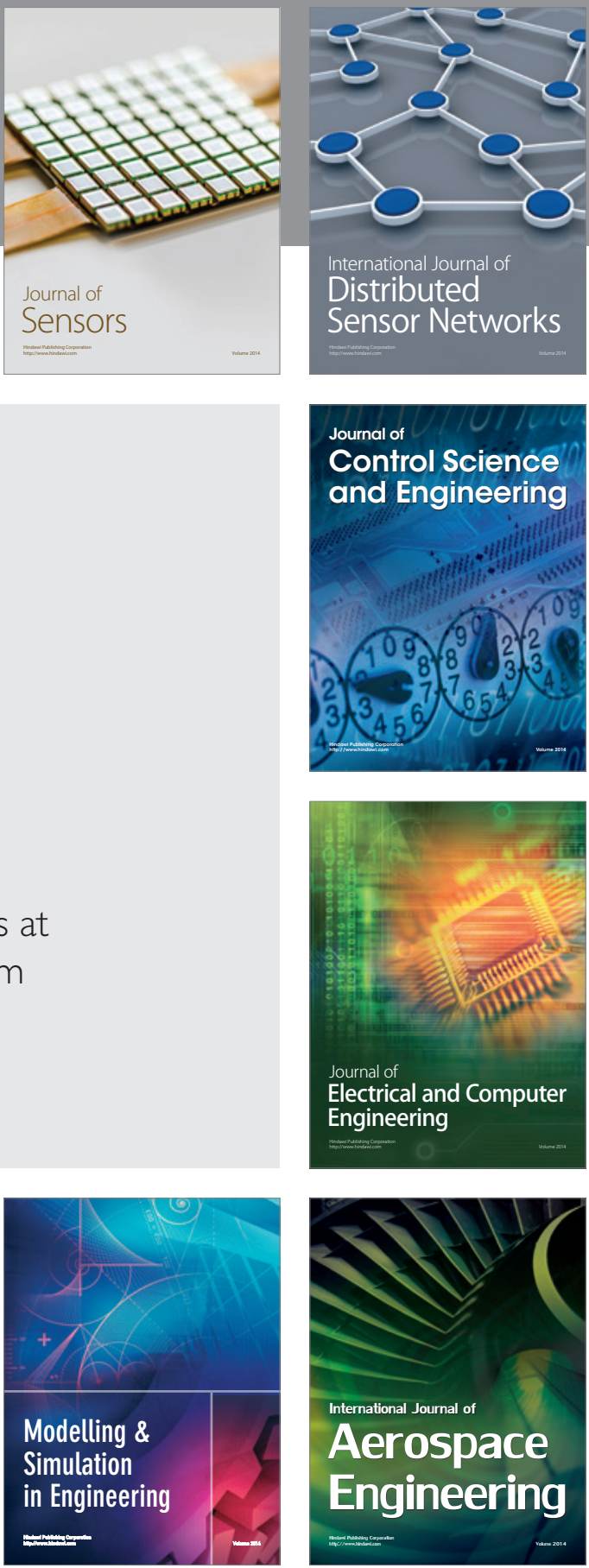

Journal of

Control Science

and Engineering
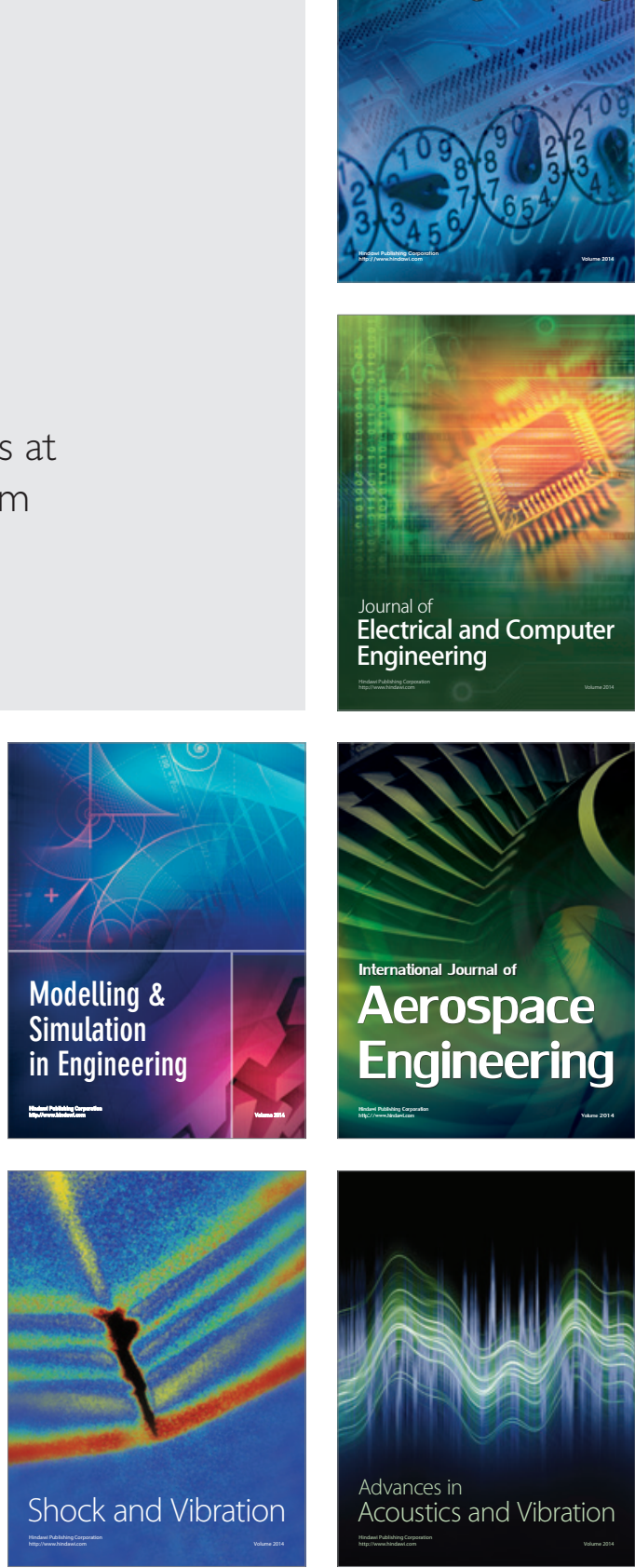